Review Article

\title{
The Effectiveness of Conbercept Combined with Panretinal Photocoagulation vs. Panretinal Photocoagulation in the Treatment of Diabetic Retinopathy: A Meta-Analysis
}

\author{
Chao Huang $\mathbb{D}^{1},{ }^{1}$ Haiqing Ji $\mathbb{D},{ }^{2}$ and Xuguang Han $\mathbb{D}^{3}$ \\ ${ }^{1}$ Department of Ophthalmology, Qilu Hospital of Shandong University, Jinan, Shandong, China \\ ${ }^{2}$ Outpatient Department, Weifang Eye Hospital, Weifang, Shandong, China \\ ${ }^{3}$ Department of Ophthalmology, Jinan Second People's Hospital, Jinan, Shandong, China
}

Correspondence should be addressed to Xuguang Han; hxg212626@126.com

Received 9 February 2021; Revised 25 April 2021; Accepted 29 April 2021; Published 10 May 2021

Academic Editor: Siamak Ansari-Shahrezaei

Copyright (c) 2021 Chao Huang et al. This is an open access article distributed under the Creative Commons Attribution License, which permits unrestricted use, distribution, and reproduction in any medium, provided the original work is properly cited.

Objective. This meta-analysis aimed to compare the effect and safety of conbercept with panretinal photocoagulation (PRP) vs. PRP in the treatment of diabetic retinopathy (DR). Methods. Relevant studies were identified through systemic searches of PubMed, EMBASE, China National Knowledge Infrastructure, and Wanfang database up to December 2020. The results of conbercept and PRP in patients with DR were analyzed, including overall effectiveness, best corrected visual acuity, central macular thickness, and complications. Results. 12 articles involving 1244 patients with DR were identified for this meta-analysis. The results of the meta-analysis showed that conbercept combined with PRP significantly increased the level of overall effectiveness and significantly reduced the central thickness of macula and the incidence of complications compared with the control group. Conclusions. Conbercept with PRP tended to be more effective than PRP alone in terms of functional outcomes for treating DR.

\section{Introduction}

Diabetic retinopathy (DR) is the most prevalent and severe ocular disorders and the major reason of adult blindness [1]. In USA, the overall 10-year incidence of retinopathy was $74 \%$, and in people with retinopathy at baseline, $64 \%$ developed more severe retinopathy and $17 \%$ progressed to develop proliferative retinopathy $[2,3]$. Due to the longterm hyperglycemia, the metabolism of capillary wall cells is disordered, and abnormal blood circulation will occur, which will affect the hardness and permeability of the retina [4]. Laser therapy has a relatively long history in the treatment of DR, and among them, the panretinal photocoagulation (PRP) was mainly applied. Based on the principle of photocoagulation, it could destroy the highconsumption retinal pigment epithelium tissue and make it scar, which can improve the state of retinal ischemia and effectively inhibit neovascularization [5]. However, drug therapy represented by antivascular endothelial growth factor (VEGF) drugs has emerged and become a hotspot in the treatment of DR in recent years.

Although laser technology can rapidly treat the lesion area, the anti-VEGF drugs can reduce the proliferation and leakage of tissue and blood vessels caused by laser surgery. It makes up for the shortcomings of laser surgery caused by temporary increase of the apparent membrane thickness and the decrease of visual acuity [6]. As an anti-VEGF fusion protein, conbercept can not only block the angiogenesis of pathological changes but also improve the blocking of ischemia and hypoxia, blood perfusion, and inflammatory cell expression [7, 8]. Conbercept ophthalmic injection is composed of humanized recombinant fusion protein, which 
can inhibit neovascularization [9]. In China, conbercept has been widely used as the first-line drug for the treatment of DR for nearly 5 years. Furthermore, some studies have reported the combination of PRP and conbercept intraocular injection could enhance the treatment effect and accelerate the recovery of vision.

To date, no systematic review has discussed the therapeutic effect and safety of conbercept versus PRP or conbercept alone in DR. Therefore, we performed this metaanalysis to quantify the efficacy and safety of conbercept and $\mathrm{PRP}$ in the treatment of DR.

\section{Materials and Methods}

A systematic search was performed to identify relevant studies of conbercept on the treatment of DR by using the following databases: PubMed, EMBASE, China National Knowledge Infrastructure, and Wanfang Data. The search included all published articles from August 2018 up to December 2020, with the following medical subject heading terms: ("conbercept" AND ("panretinal photocoagulation" OR "PRP”) AND (“Diabetic retinopathy" OR “DR")). There were no language restrictions in the research. Inclusion criteria: (1) randomized controlled trials (RCTs); (2) the type of disease was DR; (3) the treatments were conbercept combined with PRP and PRP alone; (4) therapeutic efficacy indicators can be obtained, such as overall effective rate, best vision correction, central macular thickness and complications. Exclusion criteria: (1) repeated articles; (2) summary of the meeting, comments, letters, etc; (3) animal studies that existing meta-analysis and systematic evaluation.

2.1. Data Extraction. Two independent reviewers searched the articles, assessed the quality of trials, and extracted the following data with a standardized form: author's name, publication time, sample size, age, course of diabetes mellitus, and DR. The included articles bias was evaluated by the Cochrane Collaboration's RCT bias wind assessment tool. The modified Jadad scale was used to evaluate the quality of the included studies, which contains eight aspects: (1) was the research described as randomized? (2) Was the approach of randomization appropriate? (3) Was the research described as blinding? (4) Was the approach of blinding appropriate? (5) Was there a presentation of withdrawals and dropouts? (6) Was there a presentation of the inclusion/ exclusion criteria? (7) Was the approach used to assess adverse effects described? (8) Was the approach of statistical analysis described? Studies receiving scores above five were considered of high quality.

2.2. Statistical Analysis. Stata software was used for all analyses. The total effective rate and complication effect were estimated using 95\% CI and OR value. The effects of best corrected visual acuity and central macular thickness were estimated using weighted mean difference (WMD) and 95\% CI. Random effects or fixed effects models were selected to estimate the total effects according to the heterogeneity test results. The $Q$-test and $\mathrm{I}^{2}$ test were used to estimate interstudy heterogeneity. When $P>0.1$ and $I^{2} \leq 50 \%$, the fixedeffect model was adopted. When $P<0.1$ and $I^{2} \geq 50 \%$, the random-effect model was adopted. Sensitivity analysis was used to evaluate the stability of the results. The Begger and Egger tests are used to assess publication bias. $P<0.05$ was considered as statistically significant.

\section{Results}

A total of 82 references were found after searching, and 20 duplicate references were eliminated. By reading the title and abstract, 35 unrelated references were excluded, and 27 full articles were read. According to the inclusion and exclusion criteria, 18 references were excluded, and 9 were finally included in this meta-analysis. 12 articles involving 1244 patients with DR were identified for this meta-analysis. The retrieval flow chart is shown in Figure 1. The basic information of the included studies is shown in Table 1. The patients' average age was over 50 years old, with a 6-year history of diabetes and 2year history of DR.

The articles' risk bias evaluation results are shown in Figure 2. The randomization method was described in 5 articles. All studies with complete data were described the setting of stratified seclusion and blindness. The article quality evaluation results are shown in Figure 1. The evaluation score of 5 articles was 5 , and that of 4 articles was less than 5 . The quality of the included article was medium.

5 articles reported the overall effectiveness of the two treatments. As shown in Figure 3, the fixed-effect model results showed that the overall efficiency of conbercept combined with PRP was higher than that of PRP alone, and the difference was statistically significant $(\mathrm{OR}=6.11,95 \% \mathrm{CI}$ (3.36, 11.13), $\left.P<0.0001 ; I^{2}=0.0 \%, P=0.544\right)$. There was no heterogeneity among studies.

8 articles reported changes in vision after two treatments. As shown in Figure 4(a), the random-effect model results showed that the best corrected visual acuity of conbercept combined with PRP was statistically significant greater than that of PRP alone (WMD $=0.13,95 \%$ CI $(0.09,0.18)$, $\left.P<0.0001 ; I^{2}=90.0 \%, P<0.0001\right)$, which indicated the heterogeneity existing among studies. Sensitivity analysis results are shown in Figure 4(b). The estimated total effect of each study was excluded successively within the range of $95 \%$ CI $(0.09,0.18)$, and the results were stable. No publication bias was detected by Begger test $(P=0.174)$ and Egger test $(P=0.05)$.

7 articles reported changes in central macular thickness after two treatments. As shown in Figure 5(a), the random effect model results indicated that the central thickness of the macular area was statistically significantly lower with conbercept combined with PRP than that with PRP alone $(\mathrm{WMD}=-109.15,95 \%$ CI $(-183.89,34.14), \quad P=0.0004$; $\left.I^{2}=99.7, \quad P<0.0001\right)$, which indicated the heterogeneity existing among studies. Sensitivity analysis results are shown in Figure 5(b). The estimated total effect of each study was excluded successively within the range of $95 \%$ CI $(-183.89,34.14)$, and the results were stable. No publication bias was detected by Begger test $(P=0.548)$ and Egger test $(P=0.174)$. 


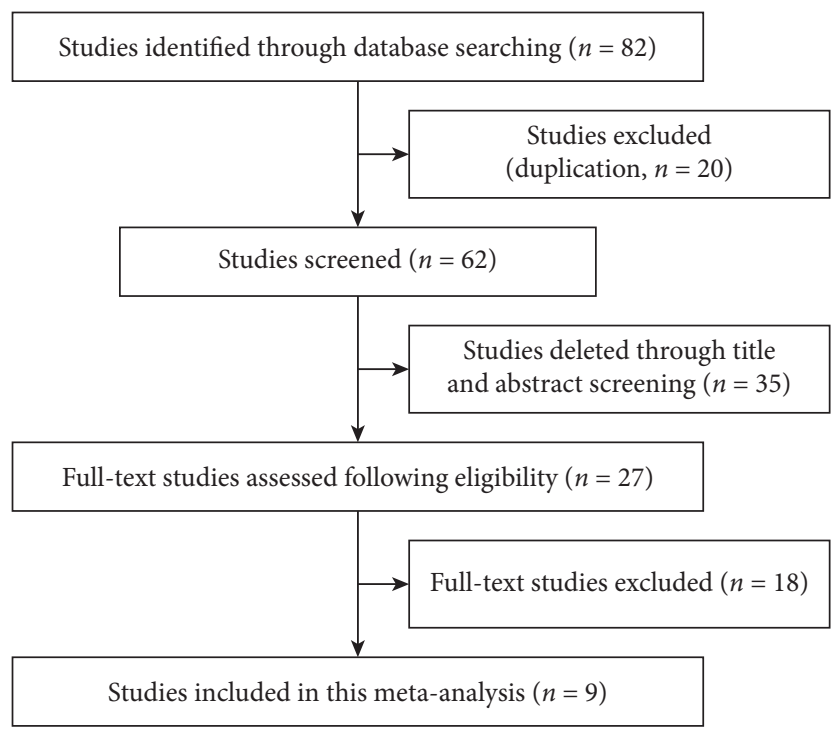

FIgURE 1: The process of selecting articles for the meta-analysis.

TABLE 1: Study baseline information was included.

\begin{tabular}{|c|c|c|c|c|c|c|c|c|}
\hline $\begin{array}{l}\text { Authors } \\
\text { (year) }\end{array}$ & Stage & Intervention & Sampling & Age (year) & Diabetic duration & $\begin{array}{c}\text { DR } \\
\text { duration }\end{array}$ & $\begin{array}{l}\text { Jadad } \\
\text { scale }\end{array}$ & $\begin{array}{c}\text { Follow- } \\
\text { up }\end{array}$ \\
\hline \multirow[t]{2}{*}{$\begin{array}{l}\text { Sun et al. } \\
(2020)\end{array}$} & \multirow[t]{2}{*}{ Proliferative } & $\begin{array}{c}0.1 \mathrm{ml} \\
\text { conbercept + PRP }\end{array}$ & 44 & $57.94 \pm 8.87$ & $8.39 \pm 1.32$ & $2.25 \pm 0.40$ & 3 & $\begin{array}{l}1 \text { month, } \\
4 \text { months }\end{array}$ \\
\hline & & $\begin{array}{l}\text { PRP: 4-5 times, every } \\
\text { other week }\end{array}$ & 44 & $58.36 \pm 8.49$ & $8.47 \pm 1.29$ & $2.20 \pm 0.41$ & & \\
\hline \multirow[t]{2}{*}{$\begin{array}{l}\text { Zhang } \\
\text { et al. } \\
(2020)\end{array}$} & \multirow[t]{2}{*}{ Proliferative } & $\begin{array}{c}0.05 \mathrm{ml} \\
\text { conbercept + PRP }\end{array}$ & 24 & $58.63 \pm 5.14$ & $10.32 \pm 1.27$ & & 3 & $\begin{array}{l}1 \text { month, } \\
3 \text { months }\end{array}$ \\
\hline & & $\begin{array}{c}\text { PRP: } 3-4 \text { times, every } \\
\text { other week }\end{array}$ & 25 & $58.47 \pm 5.10$ & $10.42 \pm 1.33$ & & & \\
\hline \multirow[t]{2}{*}{$\begin{array}{l}\text { Duan et al. } \\
(2020)\end{array}$} & \multirow[t]{2}{*}{ Proliferative } & $\begin{array}{c}0.05 \mathrm{ml} \\
\text { conbercept + PRP }\end{array}$ & 100 & $62.3 \pm 1.2$ & $6.8 \pm 1.0$ & & 3 & 1 month \\
\hline & & $\begin{array}{c}\text { PRP: 3-4 times, every } \\
\text { other week }\end{array}$ & 100 & $60.0 \pm 2.4$ & $6.2 \pm 1.2$ & & & \\
\hline \multirow[t]{2}{*}{$\begin{array}{l}\text { Liu et al. } \\
(2020)\end{array}$} & \multirow[t]{2}{*}{$\begin{array}{l}\text { Nonproliferative } \\
\text { and proliferative }\end{array}$} & $\begin{array}{c}0.05 \mathrm{ml} \\
\text { conbercept + PRP }\end{array}$ & 56 & $56.27 \pm 3.16$ & & & 5 & 1 month \\
\hline & & PRP & 56 & $57.86 \pm 3.87$ & & & & \\
\hline \multirow[t]{2}{*}{$\begin{array}{l}\text { Cui et al. } \\
(2019)\end{array}$} & \multirow[t]{2}{*}{ Proliferative } & $\begin{array}{c}0.05 \mathrm{ml} \\
\text { conbercept + PRP }\end{array}$ & 32 & $57.2 \pm 9.2$ & $8.4 \pm 3.9$ & & 5 & 1 month \\
\hline & & $\begin{array}{c}\text { PRP: } 3-4 \text { times, every } \\
\text { other week }\end{array}$ & 32 & $59.0 \pm 8.0$ & $7.8 \pm 4.5$ & & & \\
\hline \multirow[t]{2}{*}{$\begin{array}{l}\text { Ye et al. } \\
(2019)\end{array}$} & \multirow[t]{2}{*}{ Proliferative } & $\begin{array}{c}0.05 \mathrm{ml} \\
\text { conbercept + PRP }\end{array}$ & 50 & $66.05 \pm 10.23$ & & & 5 & 3 months \\
\hline & & $\begin{array}{c}\text { PRP: } 3-4 \text { times, every } \\
\text { other week }\end{array}$ & 50 & $65.84 \pm 10.45$ & & & & \\
\hline \multirow[t]{2}{*}{$\begin{array}{l}\text { Zeng et al. } \\
\text { (2018) }\end{array}$} & \multirow[t]{2}{*}{ Not applicable } & $\begin{array}{c}0.05 \mathrm{ml} \\
\text { conbercept + PRP }\end{array}$ & 40 & $61.86 \pm 12.77$ & $7.61 \pm 1.37$ & & 5 & 1 month \\
\hline & & $\begin{array}{c}\text { PRP: } 500-800 \text { points } \\
\text { per time, every other } \\
\text { week }\end{array}$ & 40 & $61.59 \pm 12.82$ & $7.57 \pm 1.29$ & & & \\
\hline \multirow[t]{2}{*}{$\begin{array}{l}\text { Liu et al. } \\
(2019)\end{array}$} & \multirow[t]{2}{*}{ Nonproliferative } & $\begin{array}{c}0.1 \mathrm{ml} \\
\text { conbercept }+\mathrm{PRP}\end{array}$ & 48 & $58.34 \pm 8.47$ & $8.45 \pm 1.27$ & $2.18 \pm 0.39$ & 5 & 1 month \\
\hline & & $\begin{array}{l}\text { PRP: } 4 \text { times, every } \\
\text { other week }\end{array}$ & 47 & $57.92 \pm 8.85$ & $8.37 \pm 1.30$ & $2.23 \pm 0.38$ & & \\
\hline
\end{tabular}


TABle 1: Continued.

\begin{tabular}{|c|c|c|c|c|c|c|c|c|}
\hline $\begin{array}{l}\text { Authors } \\
\text { (year) }\end{array}$ & Stage & Intervention & Sampling & Age (year) & Diabetic duration & $\begin{array}{c}\text { DR } \\
\text { duration }\end{array}$ & $\begin{array}{l}\text { Jadad } \\
\text { scale }\end{array}$ & $\begin{array}{l}\text { Follow- } \\
\text { up }\end{array}$ \\
\hline \multirow[t]{2}{*}{$\begin{array}{l}\text { Zhang } \\
\text { et al. } \\
\text { (2018) }\end{array}$} & Not applicable & $\begin{array}{c}0.1 \mathrm{ml} \\
\text { conbercept + PRP }\end{array}$ & 31 & $50 \pm 5$ & $6 \pm 3$ & & 4 & 3 months \\
\hline & & $\begin{array}{l}\text { PRP: } 500-800 \text { points } \\
\text { per time, every other } 5 d\end{array}$ & 31 & $49 \pm 6$ & $7 \pm 3$ & & & \\
\hline
\end{tabular}

Note. DR, diabetic retinopathy; PRP, panretinal photocoagulation.
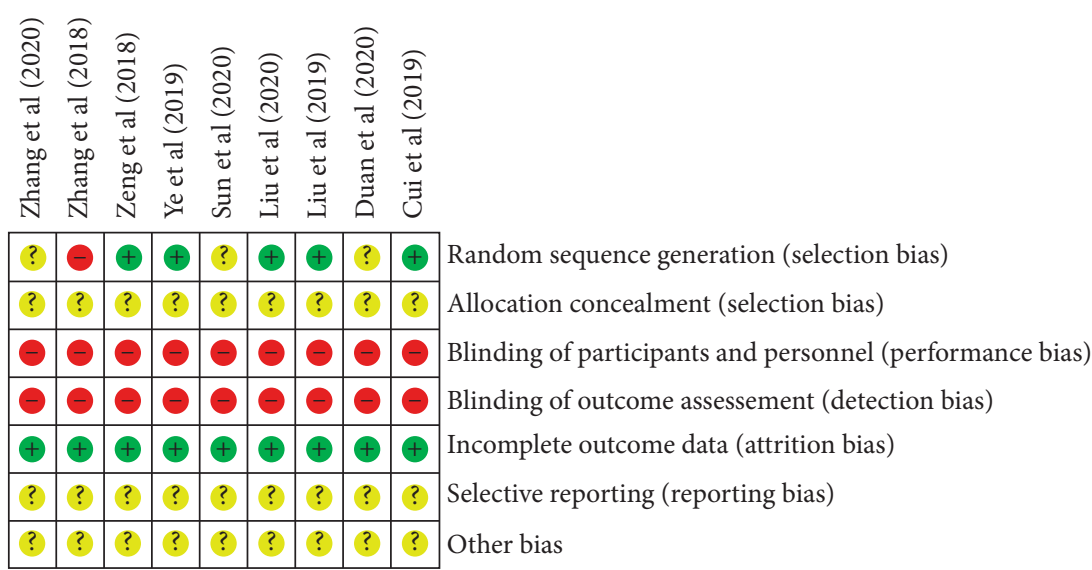

Low risk of bias

Unclear risk of bias

High risk of bias

(a)

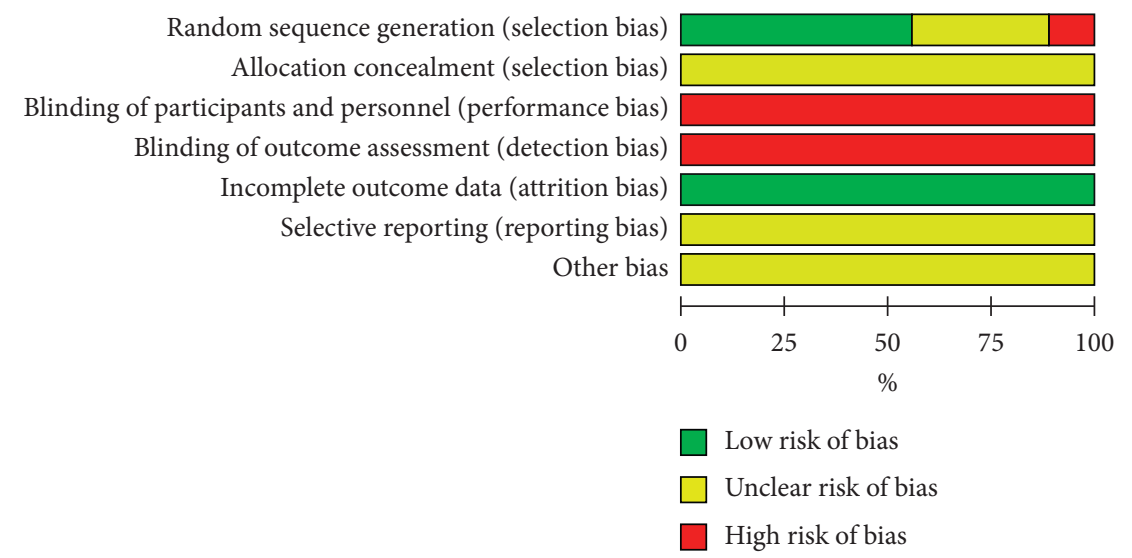

(b)

FIgURE 2: (a) The detailed characteristics of the included studies. (b) The articles' risk of bias evaluation results.

4 articles reported the incidence of complications after two treatments. As shown in Figure 6, the random effect model results showed that the complication incidence of conbercept combined with PRP was lower than that of PRP alone, but with no statistically significant difference $\left(\mathrm{OR}=0.28,95 \%\right.$ CI $(0.07,1.22), P=0.091 ; I^{2}=72.3 \%$, $P=0.013)$, which indicated the moderate heterogeneity among studies.

\section{Discussion}

DR is the leading cause of severe vision loss in patients with diabetes worldwide [10]. The increase in the number of DR patients also puts a burden on the health care system [11]. In recent years, due to a variety of factors, the prevalence of diabetes continues to rise, and the number of DR patients accordingly increases, which has a serious impact on the 


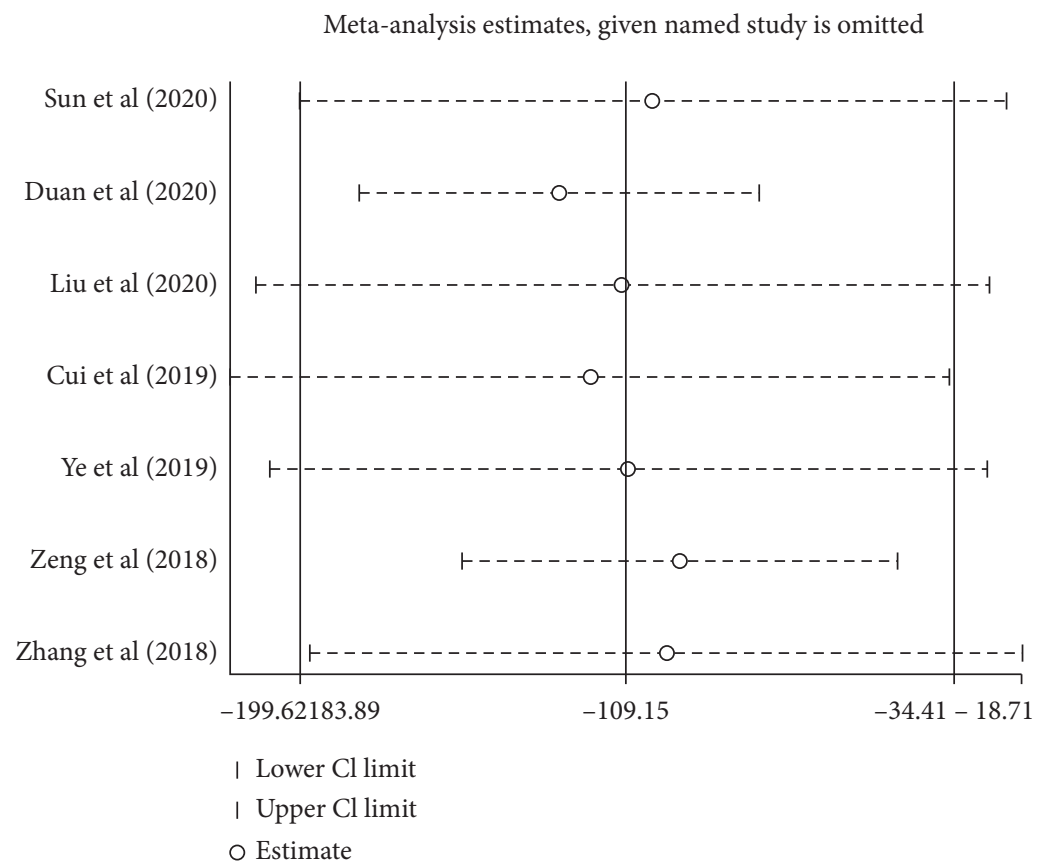

(a)

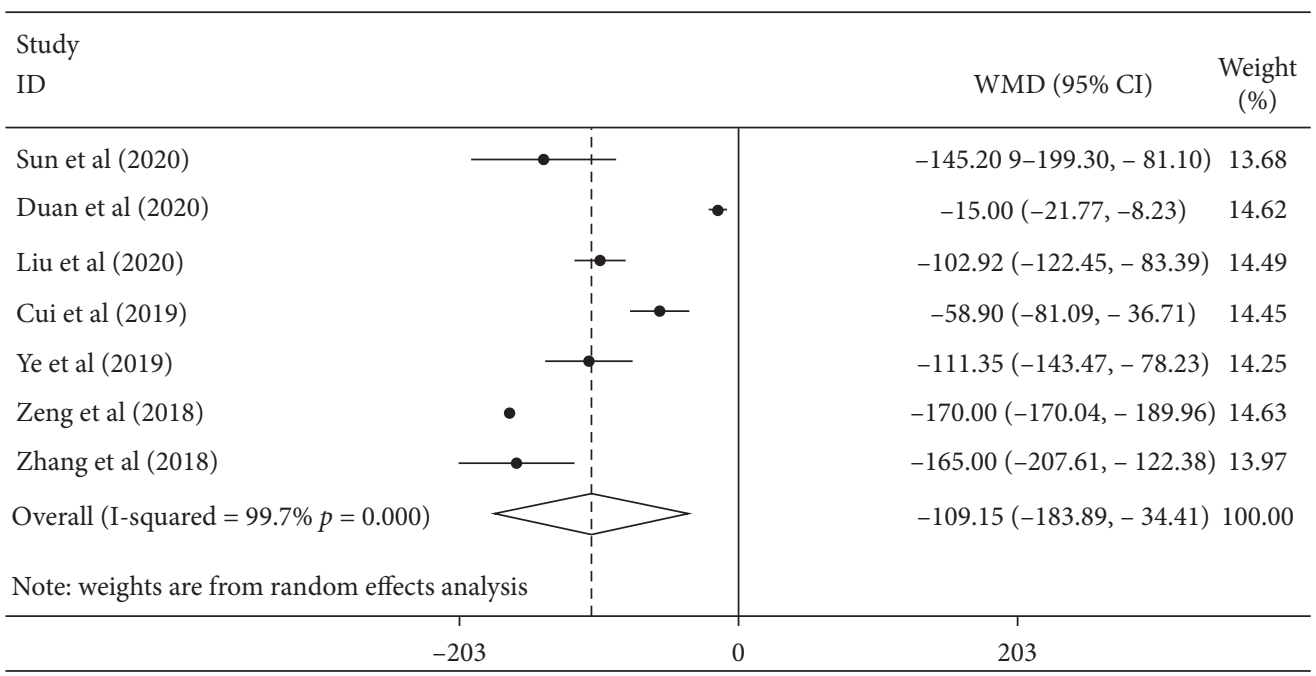

(b)

FIGURE 3: Forest plot of the overall effectiveness in conbercept treatment or compared with PRP that of DR.

quality of life of patients [12]. In the past four decades, PRP has been the standard treatment for DR, according to the American Academy of Ophthalmology's latest Diabetic Retinopathy Clinical Guidelines in 2019. It can induce the regression of neovascular and reduce the risk of severe vision loss [13]. However, He et al. and Soman et al. have indicated that PRP treatment may cause short-term macular edema $[14,15]$. Recently, anti-VEGF drugs have been shown to effectively attenuate retinal neovascularization [16, 17], and intravitreal injection of anti-VEGF agents could also be used for DR. Furthermore, previous studies found that PRP combined with antivascular endothelial growth factor (VEGF) agents such as ranibizumab was more effective for neovascular regression than PRP alone [18-20]. Therefore, it is of great significance to find a therapeutic regimen with high safety and definite efficacy to improve the quality of life of DR patients.

Conbercept belongs to the group of recombinant decoy receptors to VEGF. Conbercept is a recombinant fusion protein which consists of the second Ig domain of VEGFR1 and the 3rd and 4th Ig domains of VEGFR2 combined with the constant region. PRP plus conbercept might be a better therapeutic strategy than PRP plus sub-Tenon's triamcinolone acetonide in treating DR at the proliferative stage [21]. For patients with macular edema, conbercept can better reduce the thickness of macular fovea, improve patients' visual acuity, and improve the treatment efficiency in a short period ( 3 months) than the control group, with reliable 


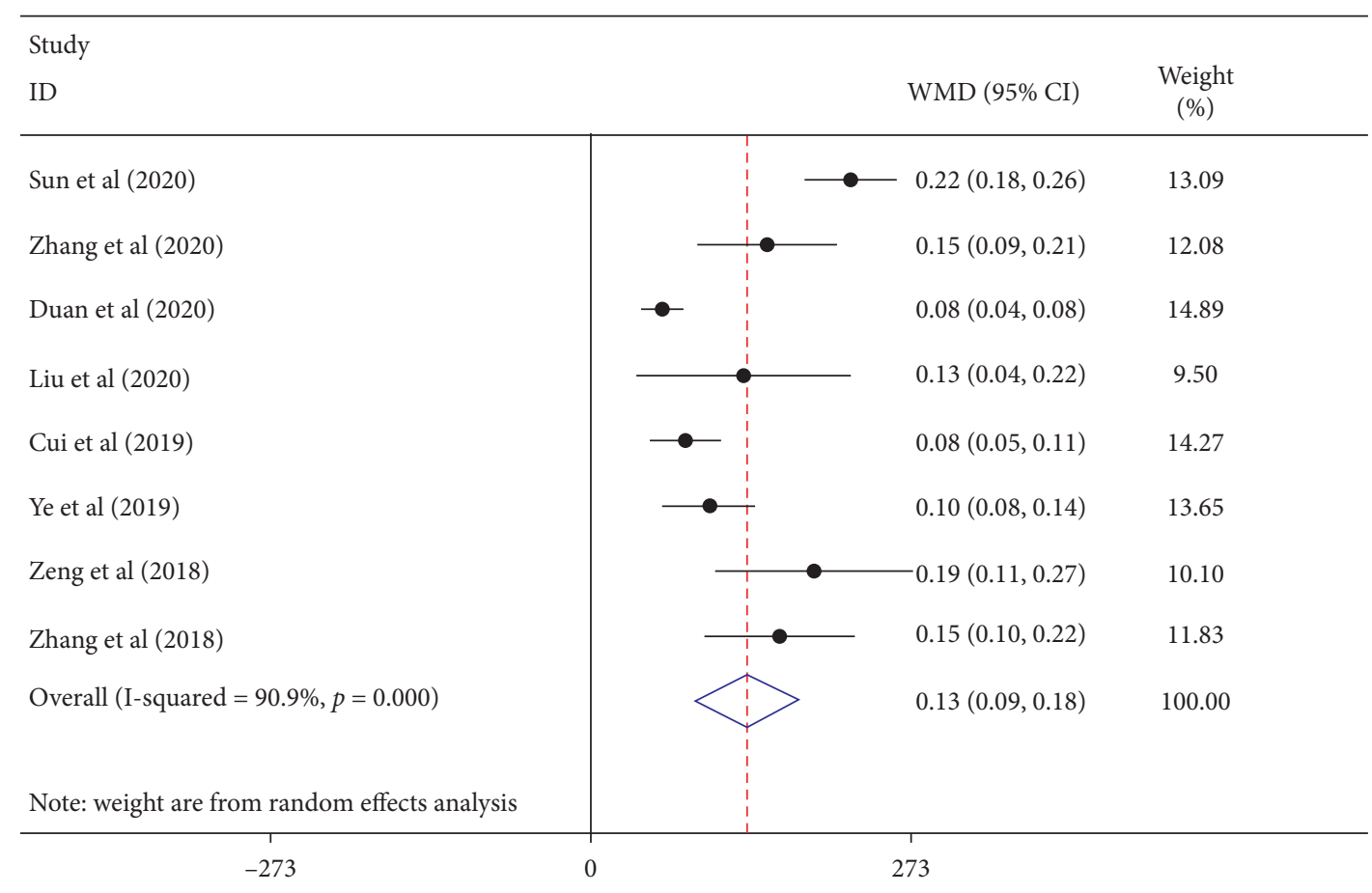

(a)

Meta-analysis estimates, given named study is omitted

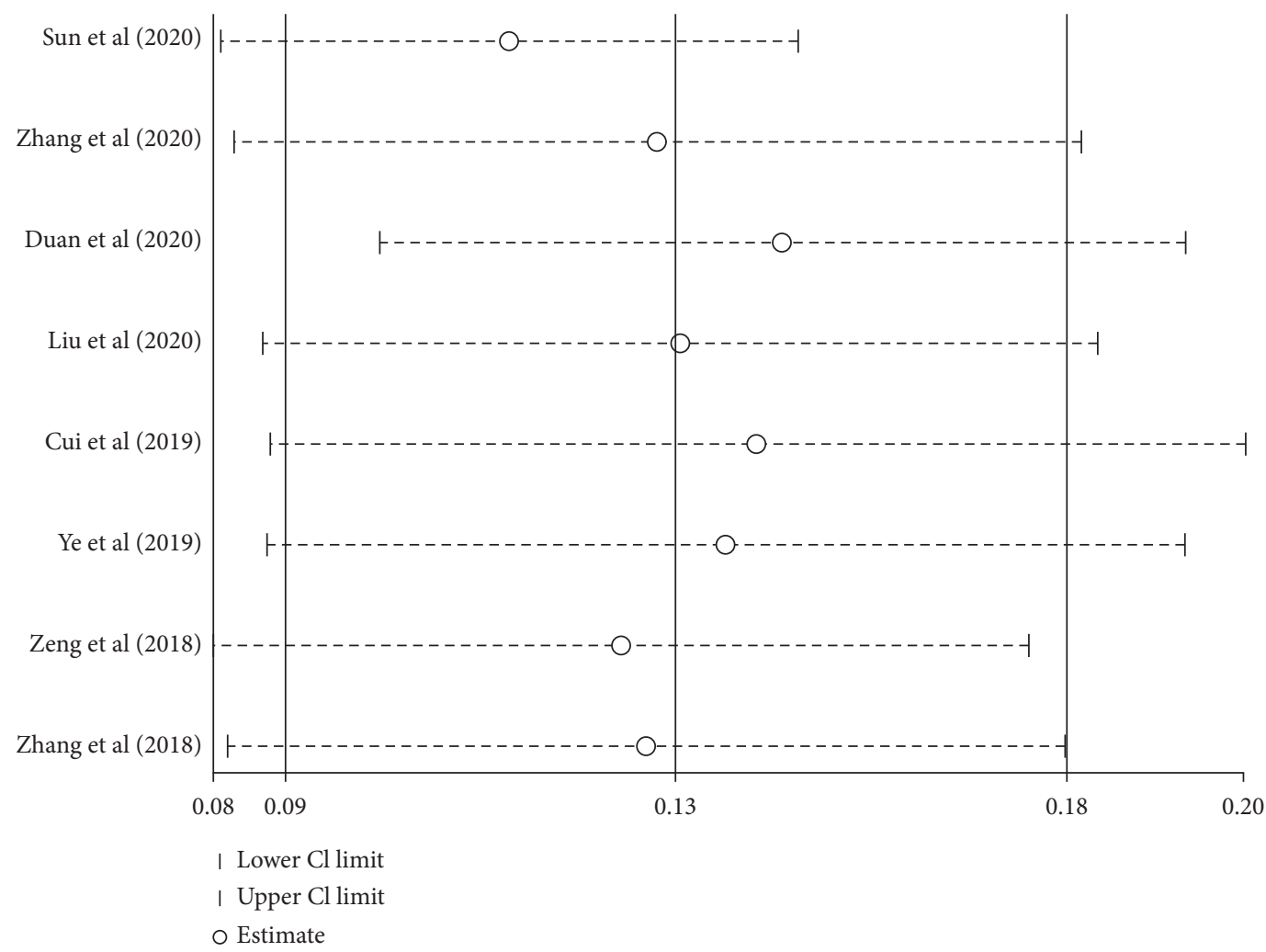

(b)

FIGURE 4: (a) Sensitivity analysis for conbercept combined with PRP was greater than that of PRP alone. (b) Forest plot of best corrected visual acuity of conbercept combined with PRP was greater than that of PRP alone. 


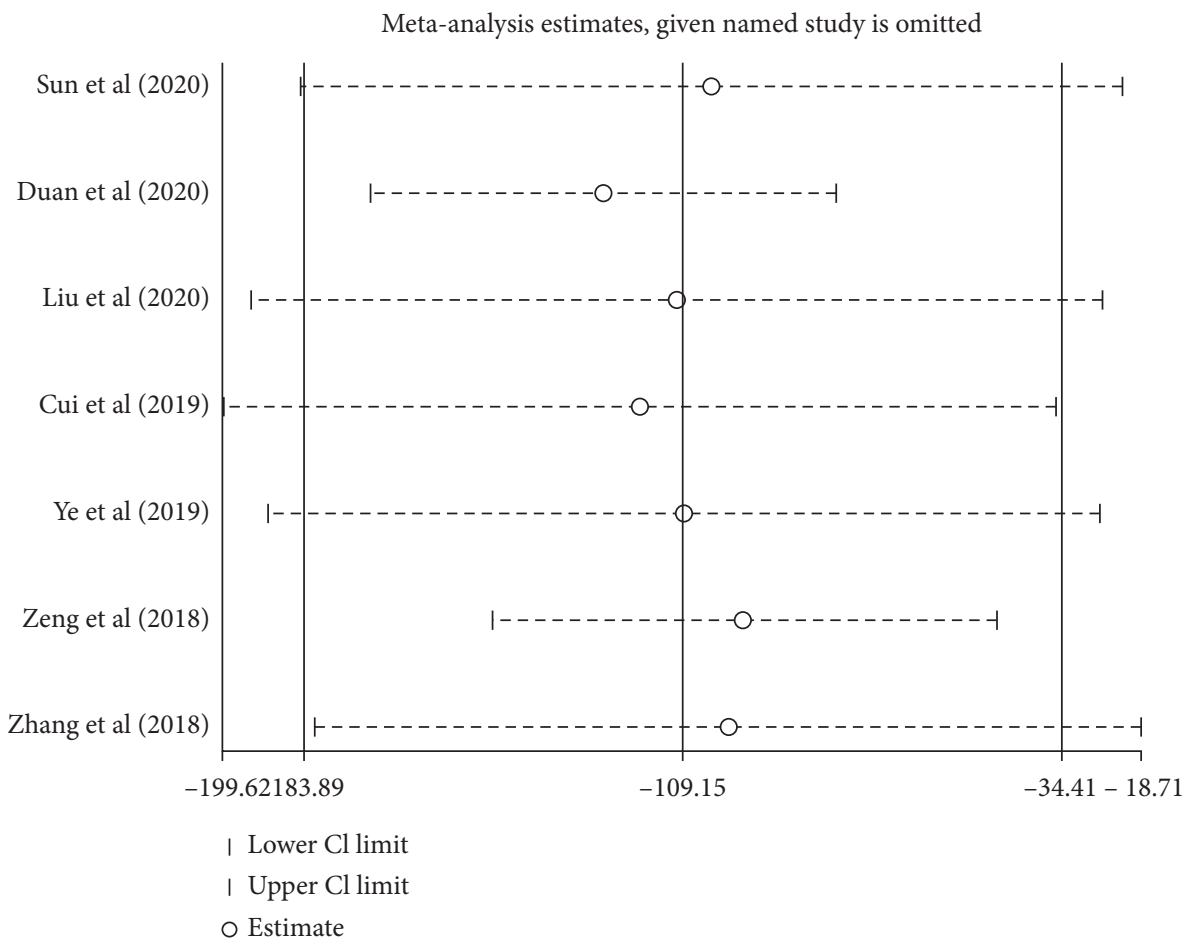

(a)

\begin{tabular}{|c|c|c|c|}
\hline \multicolumn{4}{|l|}{ Study } \\
\hline ID & & WMD $(95 \%$ CI $)$ & $\begin{array}{c}\text { Weight } \\
(\%)\end{array}$ \\
\hline Sun et al (2020) & & $-145.20(-196.30,-81.10)$ & 13.59 \\
\hline Duan et al (2020) & $\bullet$ & $-15.00(-21.77,-8.23)$ & 14.62 \\
\hline Liu et al (2020) & & $-102.92(-122.45,-83.39)$ & 14.49 \\
\hline Cui et al (2019) & $\longrightarrow-$ & $-58.90(-81.09,-36.71)$ & 14.45 \\
\hline Ye et al (2019) & & $-111.35(-143.47,-78.23)$ & 14.25 \\
\hline Zeng et al (2019) & & $-170.00(-170.04,-180.06)$ & 14.63 \\
\hline Zhang et al (2018) & & $-165.00(-207.61,-122.38)$ & 13.97 \\
\hline Overall (I-squared $=99.7 \%, p=0.000)$ & & $-109.15(-183.89,-34.41)$ & 100.00 \\
\hline \multicolumn{4}{|l|}{ Note: weights are from random effects analysis } \\
\hline-203 & ( & 203 & \\
\hline
\end{tabular}

(b)

FIGURE 5: (a) Sensitivity analysis for conbercept combined with PRP was greater than that of PRP alone. (b) Forest plot of the central macular thickness in conbercept treatment or compared with PRP that of DR.

efficacy and good tolerability [22]. In addition, many scholars have compared the efficacy of conbercept with that of PRP [23-25]. However, there is still a lack of systematic classification, collection, and evaluation of these study data. Therefore, we performed this meta-analysis to quantify the effect and safety of conbercept and PRP in the treatment of DR.
In this study, 12 articles were selected strictly according to the inclusion criteria, and 1244 patients were included, over 50 years old, with a 6-year history of diabetes, and with a 2-year history of DR. The results fully indicate that PRP combined with intravitreal injection of conbercept can effectively promote the recovery of retinal thickness, improve the maximum corrected visual acuity, significantly shorten 


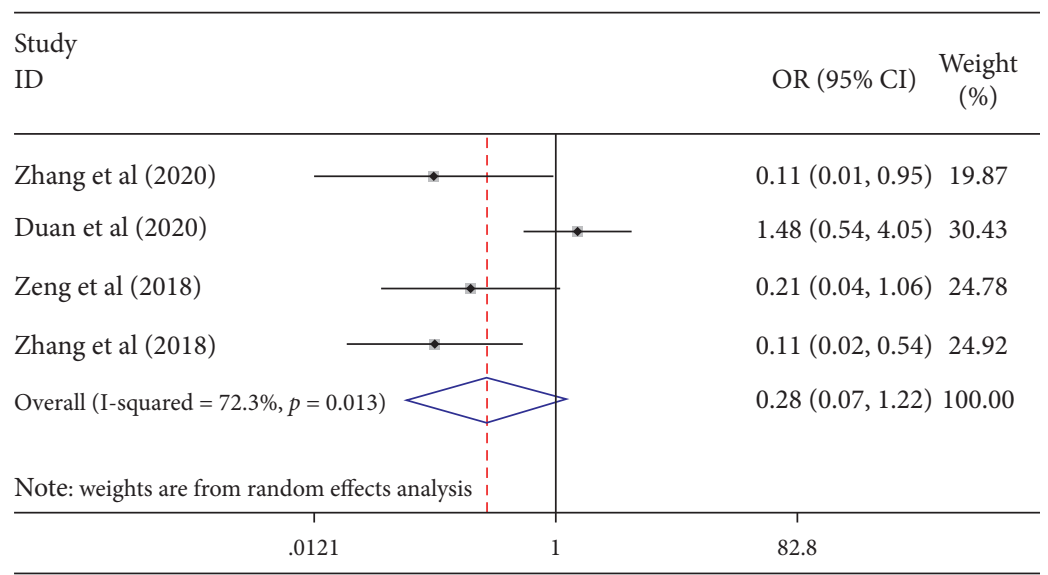

FIgURE 6: Forest plot of the complication rate of DR in conbercept treatment or combined with PRP.

the time for symptom improvement, and reduce the incidence of complications in DR patients.

Intravitreal injection of conbercept combined with PRP for macular edema secondary to BRVO is effective, safe, and superior to PRP only. It also had a longer effective duration and less complication than intravitreal triamcinolone combined with laser photocoagulation [26]. There was an article shown that the combination of the two treatments can reduce the $\log M A R$ value of the patient's vision and can significantly improve the patient's hemodynamics, oxidative stress, and inflammatory factors [27]. It is consistent with the above conclusions that PRP and intravitreal injection of conbercept in the treatment of DR may effectively promote the recovery of retinal thickness and increase the maximum corrected visual acuity. At the same time, PRP treatment can significantly shorten the time of symptom improvements and reduce the incidence of complications and serum bFGF, IGF-1, and VEGF levels [28].

\section{Conclusion}

Our results demonstrated that the conbercept combined with PRP has better efficacy than that of PRP alone. Furthermore, patients in the combined group had significantly reduced the complications and central thickness of the macular area after the treatment than the PRP group. In contrast, patients in the combined group had increased overall effectiveness. Therefore, the combined therapy could be a potentially favorable treatment therapy for DR. However, there were still the following shortcomings: there were fewer included articles and they were all open studies, so the conclusions obtained in this paper still need to be verified in a large sample randomized, double-blind, controlled study. There is no explanation about blind method in the included studies, and there is a certain risk bias in the article. In future studies, we need higher quality studies to verify our conclusions.

\section{Data Availability}

The data used to support the findings of this study are available from the corresponding author upon request.

\section{Conflicts of Interest}

The authors declare that they have no conflicts of interest.

\section{Authors' Contributions}

JHQ was responsible for study set up and design, statistical analysis, and final approval of the manuscript. HC took part in statistical analysis, drafting, and final approval of the manuscript. HXG was responsible for data collection, drafting, critical revision, and final approval of the manuscript. All authors read and approved the final manuscript.

\section{References}

[1] L. Z. Heng, O. Comyn, T. Peto et al., "Diabetic retinopathy: pathogenesis, clinical grading, management and future developments," Diabetic Medicine, vol. 30, no. 6, pp. 640-650, 2013.

[2] C. P. Wilkinson, F. L. Ferris, R. E. Klein et al., "Proposed international clinical diabetic retinopathy and diabetic macular edema disease severity scales," Ophthalmology, vol. 110, no. 9, pp. 1677-1682, 2003.

[3] N. Cheung, P. Mitchell, and T. Y. Wong, "Diabetic retinopathy," The Lancet, vol. 376, no. 9735, pp. 124-136, 2010.

[4] A. H. A. Ghamdi, "Clinical predictors of diabetic retinopathy progression; A systematic review," Current Diabetes Reviews, vol. 16, no. 3, pp. 242-247, 2020.

[5] W. Meng, R. Li, and X. Xie, "Conbercept and retinal photocoagulation in the treatment of diabetic macular edema," Pakistan Journal of Medical Sciences, vol. 35, no. 6, pp. 1493-1498, 2019.

[6] Y. Cheng, X. Zhu, D. Linghu, and J. Liang, "Comparison of the effectiveness of conbercept and ranibizumab treatment for retinopathy of prematurity," Acta Ophthalmologica, vol. 98, no. 8, pp. e1004-e1008, 2020.

[7] K. Liu, Y. Song, G. Xu et al., "Conbercept for treatment of neovascular age-related macular degeneration: results of the randomized phase 3 PHOENIX study," American Journal of Ophthalmology, vol. 197, pp. 156-167, 2019.

[8] L. Wang, C. Zhang, and R. Hua, "Clinical effectiveness of ranibizumab and conbercept for neovascular age-related macular degeneration: a meta-analysis," Drug Design, Development and Therapy, vol. 12, pp. 3625-3633, 2018. 
[9] C. Cui and H. Lu, "Clinical observations on the use of new anti-VEGF drug, conbercept, in age-related macular degeneration therapy: a meta-analysis," Clinical Interventions in Aging, vol. 13, pp. 51-62, 2018.

[10] T. W. Gardner and J. M. Sundstrom, "A proposal for early and personalized treatment of diabetic retinopathy based on clinical pathophysiology and molecular phenotyping," Vision Research, vol. 139, pp. 153-160, 2017.

[11] C. J. Flaxel, A. R. Edwards, L. P. Aiello et al., "Factors associated with visual acuity outcomes after vitrectomy for diabetic macular edema," Retina, vol. 30, no. 9, pp. 1488-1495, 2010.

[12] S. A. Agemy, N. K. Scripsema, C. M. Shah et al., "Retinal vascular perfusion density mapping using optical coherence tomography angiography in normals and diabetic retinopathy patients," Retina, vol. 35, no. 11, pp. 2353-2363, 2015.

[13] Early photocoagulation for diabetic retinopathy, "ETDRS report number 9. Early treatment diabetic retinopathy study research group," Ophthalmology, vol. 98, no. 5 Suppl, pp. 766-785, 1991.

[14] F. He, J. Yang, X. Zhang, and W. Yu, "Efficacy of conbercept combined with panretinal photocoagulation in the treatment of proliferative diabetic retinopathy," Scientific Reports, vol. 10 , no. 1 , p. $8778,2020$.

[15] M. Soman, S. Ganekal, U. Nair, and K. Nair, "Effect of panretinal photocoagulation on macular morphology and thickness in eyes with proliferative diabetic retinopathy without clinically significant macular edema," Clinical Ophthalmology (Auckland, N. Z.), vol. 6, pp. 2013-2017, 2012.

[16] J. G. Gross, J. G. Gross, A. R. Glassman et al., "Panretinal photocoagulation vs intravitreous ranibizumab for proliferative diabetic retinopathy: a randomized clinical trial," Journal of the American Medical Association, vol. 314, no. 20, pp. 2137-2146, 2015.

[17] J. K. Sun, A. R. Glassman, W. T. Beaulieu et al., "Rationale and application of the protocol S anti-vascular endothelial growth factor Algorithm for proliferative diabetic retinopathy," Ophthalmology, vol. 126, no. 1, pp. 87-95, 2019.

[18] D. A. Ferraz, L. M. Vasquez, R. C. Preti et al., "A randomized controlled trial of panretinal photocoagulation with and without intravitreal ranibizumab in treatment-naive eyes with non-high-risk proliferative diabetic retinopathy," Retina, vol. 35, no. 2, pp. 280-287, 2015.

[19] J. A. R. Filho, A. Messias, F. P. P. Almeida et al., "Panretinal photocoagulation (PRP) versus PRP plus intravitreal ranibizumab for high-risk proliferative diabetic retinopathy," Acta Ophthalmologica, vol. 89, no. 7, pp. e567-e572, 2011.

[20] J. Figueira, E. Fletcher, P. Massin et al., "Ranibizumab plus panretinal photocoagulation versus panretinal photocoagulation alone for high-risk proliferative diabetic retinopathy (PROTEUS study)," Ophthalmology, vol. 125, no. 5, pp. 691-700, 2018.

[21] S. Cai, Q. Yang, X. Li, and Y. Zhang, "The efficacy and safety of aflibercept and conbercept in diabetic macular edema," Drug Design, Development and Therapy, vol. 12, pp. 3471-3483, 2018.

[22] C. Li and Y. Zhang, "Meta-analysis of the efficacy and safety of compacseep in the treatment of macular edema," Drug Evaluation Research, vol. 41, no. 10, pp. 143-151, 2018.

[23] F. Li, L. Zhang, Y. Wang et al., "One-year outcome of conbercept therapy for diabetic macular edema," Current Eye Research, vol. 43, no. 2, pp. 218-223, 2018.

[24] P. Romero-Aroca, J. Reyes-Torres, M. Baget-Bernaldiz, and C. Blasco-Suñe, "Laser treatment for diabetic macular edema in the 21st century," Current Diabetes Reviews, vol. 10, no. 2, pp. 100-112, 2014.

[25] Y. Xu, A. Rong, Y. Bi, and W. Xu, "Intravitreal conbercept injection with and without grid laser photocoagulation in the treatment of diffuse diabetic macular edema in real-life clinical practice," Journal of Ophthalmology, vol. 2016, Article ID 2143082, 7 pages, 2016.

[26] J. Zhang, X.-j. Cai, X.-M. Chen, and T. Zheng, "A prospective randomized clinical trial on intravitreous injection of conbercept combined with laser photocoagulation for macular edema secondary to branch retinal vein occlusion," Chinese Journal of Fundus Diseases, vol. 31, no. 1, pp. 22-26, 2015.

[27] H. Wang and H. Peng, "Observation of clinical effect of fundus laser combined with compaccip in treating DR," Central South Journal of Medical Science, vol. 6, 2019.

[28] S. Zhang, L. Dai, and X. Li, "Effect of intravitreal injection of conbercept and laser photocoagulation on symptom improvements and changes of serum bFGF, IGF-1 and VEGF levels in patients with diabetic retinopathy," Medicine and Clinic in China, vol. 18, no. 10, pp. 1667-1670, 2018. 